\title{
Colour Removal of Direct Red Dye Effluent by Adsorption Process Using Rice Husk
}

\author{
V. M. Sivakumar, M. Thirumarimurugan, A. M. Xavier, A. Sivalingam, and T. Kannadasan
}

\begin{abstract}
To show that rice husk could be employed as low-cost and effective adsorbent for the removal of direct red 23 from dye effluent and also to study the effect of concentration of dye solution and the effect of amount of adsorbent on the percentage removal of dye. Azo dyes and their degradation products such as aromatic amines are highly carcinogenic. Adsorption of dyes is a new technology for treatment of waste water containing different types of dyes. Adsorption process is adopted for removal of direct red 23 dye from the dye effluent using rice husk as the adsorbent in treated and untreated form. The process involves: washing and drying of rice husk at $105^{\circ} \mathrm{C}$ followed by soaking in $0.6 \mathrm{M}$ citric acid for 2 hours and heated to $120{ }^{\circ} \mathrm{C}$. Further it is dried and washed repeatedly to obtain treated rice husk. This treated and untreated rice husk are used for removal of direct red 23 dyes. Dye solutions of different concentrations were prepared and a known amount of adsorbent were added to study the Effect of concentration of dye solution and effect of amount of adsorbent on the percentage of removal of direct red 23 .
\end{abstract}

Index Terms - Direct red dye, rice husk, adsorption, effluent treatment, microporous.

\section{INTRODUCTION}

Azo dyes and their degradation products such as aromatic amines are highly carcinogenic [9]. Adsorption of dyes is a new technology for treatment of wastewater containing different types of dyes [7]. The goal of this research is to develop a new and efficient adsorbent of direct dyes. Thus, rice husk, a commonly available agriculture waste, was investigated as viable materials for treatment of synthetic Direct F. Scarlet (Direct Red 23) containing industrial wastewater. Rice husk has many advantages such as its granular structure, chemical stability and its local availability at very low cost and there is no need to regenerate them due to their low production costs. The main constituents of rice husk are: $64-74 \%$ volatile matter and $12-16 \%$ fixed carbon and $15-20 \%$ ash [1]. Hence rice husk can be used as an effective adsorbent. Proper treatment of the dye plant effluent is thus, a matter of concern before discharge. This led to an intensive search for the best available technology, which can be used for the removal and remediation of dyes. In addition, it makes the treatment of industrial effluent to be an important target for industry and environment protection. Different treatment methods are described in the literature, including filtration, flocculation, chemical precipitation, ion exchange, membrane

Manuscript received July 17, 2012; revised October 23, 2012.

The authors are with the Department of Chemical Engineering, Coimbatore Institute of Technology, Coimbatore, India (e-mail: vmsivakumar@gmail.com, thirumarimurugan@gmail.com, as.sabhari@ gmail.com, tkannadasan56@yahoo.com, merlyxavier10@gmail.com). separation, and adsorption [11]. Practically, dye removal process requires the following potential advantages for the adsorbent: 1) a large accessible pore volume, 2) hydrophobicity, 3) high thermal and hydrothermal stability, 4) no catalytic activity, and 5) easy regeneration. New approaches based on the use of natural, inexpensive sorbent materials for effluent treatment have been reported. However, the use of these materials is still limited, although they show good adsorption capacity relative to that of the other expensive treatment processes [4]. The adsorption process is one of the efficient methods to remove contaminant from effluent [7]. The process of adsorption has an edge over the other methods due to its sludge free clean operation and complete removal of dye even from dilute solutions. Activated carbon is the most widely used adsorbent for this purpose because of its extended surface area, microporous structure, high adsorption capacity and high degree of surface reactivity. However, commercially available activated carbons are very expensive. In addition, the laboratory preparation of activated carbons have been accompanied by a number of problems such as combustion at high temperature, pore blocking, and hygroscopicity. This has led to search for cheaper and simplest substituent. Rice husk, an undesirable agriculture mass residue in Egypt, is a by-product of the rice milling industry. It is one of the most important agricultural residues in quantity. It represents about $20 \%$ of the whole rice produced, on weight basis of the whole rice [2]. The estimated annual rice production of 500 million tons in developing countries, approximately 100 million tons of rice husk is available annually for utilization in these countries aloe. Traditionally, rice husks have been used in manufacturing block employed in civil construction as panels and was used by the rice industry itself as a source of energy for boilers [3]. However, the amounts of rice husk available are so far in excess of any local uses and have posed disposal problems. It was chosen because of its granular structure, chemical stability and its local availability at very low cost and there is no need to regenerate them due to their low production costs. The main constituents of rice husk are: $64-74 \%$ volatile matter and $12-16 \%$ fixed carbon and $15-20 \%$ ash [2]The rice husk composition are: $32.24 \%$ cellulose, $21.34 \%$ hemicellulose, $21.44 \%$ lignin, $1.82 \%$ extractives, $8.11 \%$ water and $15.05 \%$ mineral ash (Govindarao 1980; Rhman et al. 1997; Nakbanpote et al. 2000). The mineral ash is 94.5-96.34\% $\mathrm{SiO} 2$. The purpose of this work is to investigate the adsorption capacity of the untreated and activated rice husk on adsorption of direct dyes from aqueous solution. Direct F. Scarlet (Direct red 23) dye was selected for the adsorption experiment due to its presence in several industrial effluents such as textile, tannery, paper, soap, cosmetics, 
polishes, wax etc. As Direct F. Scarlet has diazo group, it has toxicity and carcinogenic nature. The dye (DR-23), dose will not allow sunlight to pass through and thereby affects the photosynthesis of aquatic plants. Modern dyes are resistant to conventional biological treatment but these azo dyes are reduced to colourless primary amines by this treatment. These primary amines are even more toxic than the original dye. The equilibrium and kinetics of DR-23 adsorption on rice husk were investigated. The Langmuir model was used to fit the equilibrium isotherm. The batch contact time method was used to measure the adsorption rate and kinetic parameters which were then evaluated.

\section{MATERIALS AND METHODS PREPARATION OF ADSORBENTS}

Rice husk was obtained from local rice mills and was washed several times with water followed by filtration. The cleaned rice husk was oven dried completely at $105^{\circ} \mathrm{C}$, then cooled and sieved to $250 \mu \mathrm{m}$ to $500 \mu \mathrm{m}$ size, which was used without further treatment. Another part of same size fraction of rice husk [5] was exposed to activation using citric acid which was reported as follows: $100 \mathrm{~g}$ of rice husk were soaked in $0.6 \mathrm{M}$ citric acid for 2 hours at $20^{\circ} \mathrm{C}$. [8] The acid-husk slurry was dried overnight at $50^{\circ} \mathrm{C}$ and the dried husk was then heated to $120^{\circ} \mathrm{C}$. The reacted product was washed repeatedly with distilled water (200 ml per $\mathrm{g}$ of husk) to remove any excess of citric acid followed by oven drying overnight at $100^{\circ} \mathrm{C}$.

\section{Preparation of Dye Solution}

The molecular formula of dye is $\mathrm{C}_{35} \mathrm{H}_{25} \mathrm{~N}_{7} \mathrm{Na}_{2} \mathrm{O}_{10} \mathrm{~S}_{2}$ and its colour index is C.I. 29160. A stock solution of the dye was prepared by dissolving 1 gram of dye in $1000 \mathrm{ml}$ distilled water to make a stock solution of $1000 \mathrm{mg} / \mathrm{l}$. The experimental solution was prepared by diluting definite volume of the stock solution to get the desired concentration. For the preparation of 50ppm solution from stock solution, the stock solution is diluted by 20 times i.e. $5 \mathrm{ml}$ of stock solution is diluted to $100 \mathrm{ml}$. Similarly $100 \mathrm{ppm}$ and $150 \mathrm{ppm}$ of solution WASS prepared.

\section{PRODEDURE}

The experimental set up involves the usage of glass wares (Conical flasks, Measuring cylinders, Pipettes, Standard flasks, Funnel, Stopper bottles, porcelain dish and test tubes etc.,) made of Borosil and certain equipment and instruments such as UV-VIS Spectrophotometer, Centrifugal Separator, Dry air Oven, Muffle Furnace, Mechanical Shaker and Weighing Machine. Dye solutions of different concentrations (50ppm, 100ppm, 150ppm) were prepared from the stock solution by diluting it with required amount of water depending on concentration and they were taken in various labelled stopper bottles. The concentrations of these standard concentration solutions (50 ppm, 100 ppm $150 \mathrm{ppm}$ ) were measured using UV-Vis Spectrophotometer at $507 \mathrm{~nm}$. Then three kinds of studies were done, i) Effect of Concentration of Solution. ii) Effect of Amount of Adsorbent. iii) Effect of Treated and Un-Treated Rice Husk. Particular amount of treated and untreated rice husk were added to each of the respective labelled bottles as defined below:

\section{$\mathrm{A}=2$ gram Un-Treated Rice Husk $+100 \mathrm{ml}$ 50ppm SOLN \\ $\mathrm{B}=2$ gram Un-Treated Rice Husk $+100 \mathrm{ml}$ 100ppm SOLN $\mathrm{C}=2$ gram Un-Treated Rice Husk $+100 \mathrm{ml}$ 150ppm SOLN $\mathrm{D}=4$ gram Un-Treated Rice Husk $+100 \mathrm{ml}$ 100ppm SOLN E=6gram Treated Rice Husk +100 ml 100ppm SOLN 1=2gram Treated Rice Husk $+100 \mathrm{ml}$ 50ppm SOLN \\ 2=2gram Treated Rice Husk $+100 \mathrm{ml}$ 100ppm SOLN \\ 3=2gram Treated Rice Husk $+100 \mathrm{ml}$ 150ppm SOLN \\ 4=4gram Treated Rice Husk $+100 \mathrm{ml}$ 100ppm SOLN \\ 5=6gram Treated Rice Husk $+100 \mathrm{ml}$ 100ppm SOLN}

These bottles were shaken physically and then followed by mechanical shaking using a mechanical shaker for about 2 hours and was let still for few hours. A small amount was withdrawn from the respective bottles and then was centrifuged at $3000 \mathrm{rpm}$ for about $10 \mathrm{~min}$. Then these samples were analyzed for concentration dye contents using $\mathrm{UV}$-Spectrophotometer at $507 \mathrm{~nm}$. The respective value gives us the study for Effect of Concentration of Solution and the Effect of amount of Adsorbent for Un-Treated and Treated Rice Husk.

\section{RESUlTS AND DisCUSSIONS}

The results obtained from the present investigation revealed the ability of rice husk in treating azo dye effluents, e.g. Direct Red-23 dye. It was found that adsorption is highly dependent on the contact time, adsorbent dose and dye concentration. The adsorption isotherm of DR-23 onto rice husk biomass is described by the Langmuir isotherm model. Kinetics of adsorption follows Lagergren first order kinetic model with film diffusion being the constitutive rate-controlling step. The monolayer adsorption capacity obtained from Langmuir isotherms for DR-23 was relatively higher for the citric acid [6] treated rice husk compared to that obtained without chemical treatment. Consequently, safety can point to the use of this natural material due to abundance and very cheap biomass. This leads to its superiority as a potential sorbent in removal of some coloured dyes from waste waters. Thus from the above conducted experiment It can be concluded that the rice husk can be used as a very effective absorbent in both treated and un-treated form. The experiment was conducted and the values were tabulated, from the tabulated values the following conclusions are being done.

TABLE I: ABSORBANCE VALUES OF STANDARD SOLUTIONS

\begin{tabular}{|c|c|}
\hline CONC. & ABSORBANCE \\
\hline 50 & 0.818 \\
\hline 100 & 1.565 \\
\hline 150 & 2.351 \\
\hline
\end{tabular}

The values of the absorbance from the UV-Vis Spectrophotometer for all the study bottles are plotted in the graph that shows the amount of colour removed by the respective adsorbent and its amount. The value shows that more the concentration of dye, more colour is removed for a given amount of adsorbent. This is because for higher concentration of solution, higher the number of dye molecules 
to interact with the adsorbent particles.. It also infers that the Treated rice husk removes more color compared to the Un-Treated rice husk. This is because of more effective adsorptive capacity for the Treated rice husk compared to the Un-Treated rice husk. This project can be further continued by making further studies on the color removal of Direct Red 23 dye by adopting other processes such as flocculation, chemical precipitation, ion exchange, membrane separation. Further studies is also to be continued on increasing the adsorption capacity of the rice husk by treating it with other acids .Studies have to be further continued to find out if rice husk can also be used for removal of other dyes. Conclusively, the expanding of rice husk ash in the field of adsorption science represents a viable and powerful tool, leading to the superior improvement of pollution control and environmental preservation.

TABLE II: Absorbance VAlues of Dye SOlutions

\begin{tabular}{|c|c|}
\hline Label & Absorbance \\
\hline A & 0.655 \\
\hline B & 1.159 \\
\hline C & 1.719 \\
\hline D & 0.754 \\
\hline E & 0.511 \\
\hline 1 & 0.576 \\
\hline 2 & 0.997 \\
\hline 3 & 1.422 \\
\hline 4 & 0.559 \\
\hline 5 & 0.464 \\
\hline
\end{tabular}

TABLE III: EFFECT OF CONCENTRATION OF SOLUTION.

\begin{tabular}{|c|c|c|c|c|c|c|}
\hline \multirow{2}{*}{$\begin{array}{c}\text { Initial } \\
\text { Conc. }\end{array}$} & ABS. & $\begin{array}{c}\text { Conc } \\
\text { (PPM) }\end{array}$ & \% Removal & ABS. & $\begin{array}{c}\text { Conc } \\
\text { (PPM) }\end{array}$ & \% Removal \\
\cline { 2 - 7 } & 0.655 & 42 & 16 & 0.576 & 37 & 26 \\
\hline 50 & 1.159 & 74 & 26 & 0.997 & 63.5 & 36.5 \\
\hline 100 & 1.719 & 110 & 26.67 & 1.422 & 91.5 & 39 \\
\hline
\end{tabular}

TABLE IV: EFFECT OF AMOUNT OF ADSORBENT.

\begin{tabular}{|c|c|c|c|c|c|c|}
\hline \multirow{2}{*}{ Initial Conc. } & \multicolumn{3}{|c|}{ Untreated } & \multicolumn{2}{c|}{ Treated } \\
\cline { 2 - 7 } & ABS. & $\begin{array}{c}\text { Conc } \\
\text { (PPM) }\end{array}$ & \% Removal & ABS. & (PPM) & \% Removal \\
\hline 2 & 1.159 & 74 & 26 & 0.997 & 63.5 & 36.5 \\
\hline 4 & 0.754 & 48 & 52 & 0.559 & 36 & 64 \\
\hline 6 & 0.511 & 32.5 & 67.5 & 0.464 & 30 & 70 \\
\hline
\end{tabular}

\section{A. Effect of Concentration of Solution}

The effect of concentration of solution is shown in Table III. Also the effect of concentration of solution is plotted in the graph which is shown as Fig. 1.

\section{B. Effect of Amount of Adsorbent}

The effect of amount of adsorbent is shown in Table IV also plotted in the graph which is shown as Fig. 2.

\section{REFERENCES}

[1] L. Armesto, A. Bahillo, K. Veijonen, A. Cabanillas, and J. Otero, "Combustion behaviour of rice husk in a bubbling fluidized bed," Biomass and Bioenergy, vol. 23, pp. 171-179, 2002.

[2] A. A. M. Daifullah, B. S. Girgis, and H. M. H. Gad, "Utilization of agro- residues (rice husk) in small wastewater treatment plans," Material Letters, vol. 57, pp. 1723-1731, 2003.

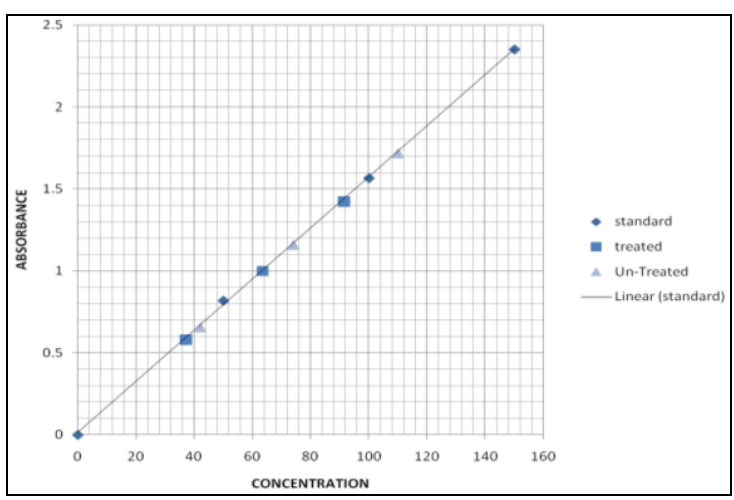

Fig. 1. Effect of concentration of solution.

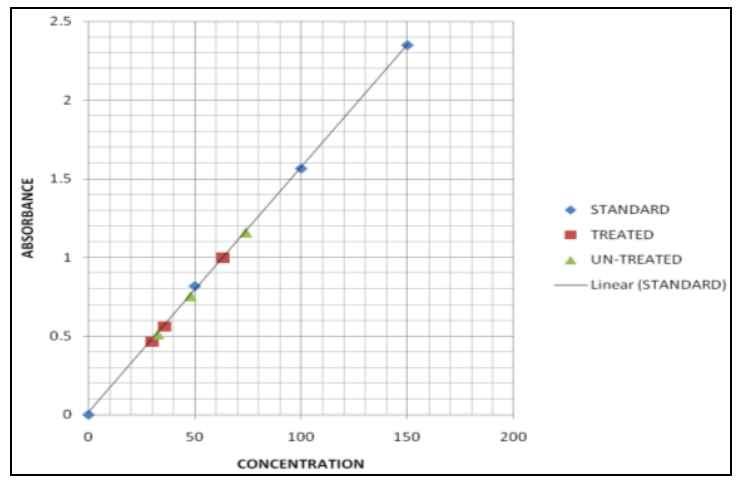

Fig. 2. Effect of amount of adsorbent.
[3] V. P. Della, I. Kuhn, and D. Hotza, "Caracterizacao de cinza de casca de arrozparausocomomateria-prima nafabricacao de refatarios de silica," Quim Nova, vol. 24, pp. 778-782, 2001

[4] V. Dushenkov, P. B. A. N. Kumar, H. Mott, and I. Raskin, "Rhizo filtration: the use of plants to remove heavy metals from aqueous streams," Environmental Science and Technology, vol. 29, pp 1239-1245, 1995.

[5] V. M. H. Govindarao, "Utilization of rice husk - a preliminary analysis," J. Science Industrial Research, vol. 39, pp. 495-515, 1980.

[6] W. E. Marshall, L. H. Wartelle, D. E. Boler, M. M. Johns, and C. A. Toles, "Enhanced metal adsorption by soybean hull modified with citric acid," Bioresource Technology, vol. 69, pp. 263-268, 1999.

[7] P. K. Malik, "Use of activated carbons prepared from sawdust and rice-husk for adsorption of acid dyes: a case study of acid yellow 36, Dyes and Pigments, vol. 56, pp. 239-249, 2003.

[8] W. E. Marshall and L. H. Wartelle, "Acid recycling to optimize citric acid modified soybean hull production," Industrial Crops and Products, vol. 18, pp. 177- 182, 2003.

[9] M. M. Mohamed, "Acid dye removal: Comparison of surfactant-modified mesoporous FSM-16 with activated carbon 
derived from rice husk," J. Colloid and Interface Science, vol. 272, pp. $28-34,2004$

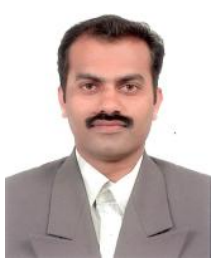

V. M. Sivakumar received his B.E. degree in chemica engineering from Annamalai University in 1998, India. Further, his M.Tech. degree in chemical engineering from Bharathiar University, India in 2000 and pursued his Ph.D. (Chemical Engineering) at Universiti Sains Malaysia (USM), Malaysia (2007 - 2010). He joined Coimbatore Institute of Technology (CIT) as a Lecturer in the Department of Chemical Engineering in the year 2000 and at present as Assistant Professor in Chemical Engineering. His areas of research are Catalysis \& Reaction Engineering, Environmental Engineering, Nanomaterials and Nanotechnology. One of his priority research areas is to conduct fundamental studies in developing effective catalysts for growing carbon Nanotubes (CNTs) from natural gas. His research outcomes has got published in leading peer-reviewed Journals like Materials Letters, Journal of Nanomaterials, Chemical Papers, Reviews on Advanced Materials Science, etc. $\mathrm{He}$ is the Member of Asia Pacific Chemical, Biological and Environmental Engineering Society (APCBEES), Life member of Indian Institute of Chemical Engineers.

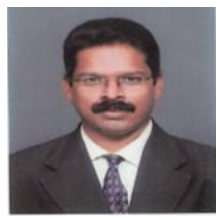

M. Thirumarimurugan was born in Tamil Nadu India. He has completed his B.Tech and M.Tech degrees in Chemical Engineering from Bharathiar University, Coimbatore in 1995 and 1997, respectively. He pursued his Ph.D. in Heat Transfer from Anna University Chennai, Chennai. He has 17 years of teaching experience and currently holds the post of Associate professor in Department of Chemical Engineering, at Coimbatore Institute of Technology, Coimbatore. He has authored One book, 13 International journals, 3 National journals, 51 conference proceedings. He has guided 16 PG projects, 22 UG projects, 4 mini projects and he is currently guiding $5 \mathrm{Ph} . \mathrm{D}$. research projects. He has also organized 6 Conferences, short-term courses. He has attended 26 conferences, summer/winter school, QIP courses and Workshops. Dr. M Thirumarimurugan is a Life Member in IICh.E and a Member in Indian Society for Technical Education. He got II best paper award in Energy and Environment in National Conference.

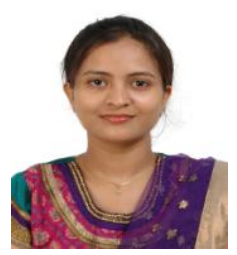

A. Merly Xavier was born in Tamil Nadu, India. She is an undergraduate student doing her final year B.Tech. degree in Chemical Engineering in Coimbatore Institute of Technology, Coimbatore. Her area of interest includes Heat transfer and Chemical Reaction Engineering. She has presented papers in CHEMCON 2011. She has also presented more than 5 oral papers. Ms. Merly Xavier is a member of IIChE.

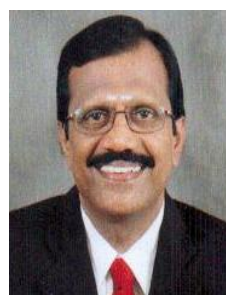

A. Sivalingam was born in Tiruppur district, Tamil Nadu, India in 1958. He completed his B.Tech. degree in chemical engineering from Madras University, Chennai in the year 1981, completed M.Tech. degree in chemical engineering from Anna University, Chennai in the year 1983 and was awarded the Ph.D. degree in chemical engineering from Anna university of Technology , Coimbatore in the year 2011. He has 28 years of teaching service with one year Industrial experience. He is currently the Associate Professor, Department of Chemical Engineering, Coimbatore Institute of Technology Coimbatore, Tamil Nadu. He has published "Mass Transfer Studies in Three Phase Fluidized Bed Using Response Surface Method", Chemical and Biochemical Engineering Quarterly, "A Study on Pressure Coefficient in Co-current Three Phase Fluidization by Linear Regression Analysis".. He has guided more than 28 Post graduate and 66 Under Graduate students' projects. Dr. Sivalingam is the Member of Asia Pacific Chemical, Biological and Environmental Engineering Society (APCBEES), Life member of Indian Institute of Chemical Engineers and Indian society of Technical Education. He has won the best teacher award during the Academic year 1999-2000. He is also a Reviewer of Chemical Engineering Communications.

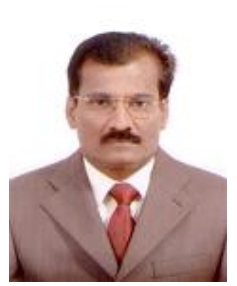

T. Kannadasan was born in 1955 in Madurai, Tamil $\mathrm{Nadu}$, India. He has completed his B.E. degree in Chemical Engineering from Annamalai University, Chidambaram, completed M.Tech. degree in chemical engineering from University of Madras, Chennai and was awarded the Ph.D. degree in chemical engineering from Annamalai University, Chidambaram. He has served as Management Trainee at M/s Gangappa Paper Mills Ltd. He has served in various Capacities from Associate Lecturer to Assistant Professor in Coimbatore Institute of Technology, Coimbatore, as Professor (PG Course) in Chemical Engineering at Coimbatore Institute of Technology, Coimbatore. He has served the post of Controller of Examinations-Additional charge University Departments of Anna University of Technology, Coimbatore. Currently he is the Professor and Head of Chemical Engineering Department at Coimbatore Institute of Technology, Coimbatore, Tamilnadu, India. He has guided 20 M.Tech. Thesis in various areas of chemical engineering. He has guided 13 Ph.D. Thesis out of which 8 are completed and 5 are still going on. Dr. Kannadasan is a Life member of Indian Institute of Chemical Engineers (IICh.E), Indian Society for Technical Education and The Institution of Engineers (India), senior member of Asia Pacific Chemical and Biological \& Environmental Engineering Society (APCBEES). 